\section{BMJ Open}

Respiratory

Research

\title{
A qualitative study of informal caregivers' perspectives on the effects of idiopathic pulmonary fibrosis
}

\author{
Amanda Belkin, ${ }^{1}$ Karen Albright, ${ }^{2,3}$ Jeffrey J Swigris ${ }^{1}$
}

To cite: Belkin A, Albright $K$, Swigris JJ. A qualitative study of informal caregivers' perspectives on the effects of idiopathic pulmonary fibrosis. BMJ Open Resp Res 2013:1:e000007.

doi:10.1136/bmjresp-2013000007

Received 20 September 2013 Accepted 25 November 2013

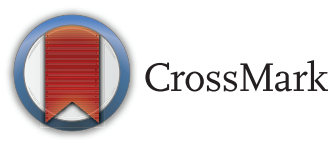

${ }^{1}$ Autoimmune Lung Center and Interstitial Lung Disease Program, National Jewish Health, Denver, Colorado, USA

${ }^{2}$ Department of Community and Behavioral Health, Colorado School of Public Health, Aurora, Colorado, USA

${ }^{3}$ Colorado Health Outcomes Program, University of Colorado School of Medicine, Aurora, Colorado, USA

Correspondence to Dr Jeffrey J Swigris; swigrisj@njc.org

\section{ABSTRACT}

Background: Idiopathic pulmonary fibrosis (IPF) is a life-shortening lung disease that leads to significant morbidity in patients. The devastation IPF imposes extends beyond patients: it affects their spouses, loved ones and any other person who might take on the role of informal caregiver (IC) to the patient.

Objective: The aim of this study was to capture ICs' perspectives on how they are affected by having a loved one with IPF. Given ICs' vantage, data were also collected on their perceptions of how IPF impacted their patient-loved ones over the course of the disease. Methods: Reflexive team analysis was used to analyse the transcripts from semistructured focus groups conducted with ICs of patients with IPF. Based on the analyses, a conceptual framework of the IC's journey with a patient with IPF was developed and includes suggestions for interventions that might ease the burdens ICs endure while caring for their patient-loved ones.

Results: 14 ICs included in this study experienced several hardships throughout the course of their loved ones' illness, from emotional devastation at the time of diagnosis to living with an 'impatient,' 'cranky' loved one and being forced to exist in a 'smaller world' because of the physical limitations IPF imposed on their partners. The threat of patients needing supplemental oxygen was central to creating angst among patients and ICs, and supplemental oxygen use by patients prohibited them and their ICs from living the 'normal', carefree lives they desired.

Conclusions: Being an IC to a patient with IPF is extremely challenging (as 1 IC put it: "...harder on the spouse than the patient in some ways"). As patients attempt to adapt to the 'sick person' role, ICs face a struggle between performing their duties as caregiver and maintaining their own identities and independence.

\section{INTRODUCTION}

Idiopathic pulmonary fibrosis (IPF) is an interstitial lung disease in which the normally delicate walls of the pulmonary alveoli are replaced by thick, mature collagen, making the lungs stiff and prohibiting diffusion of oxygen from airspace to the bloodstream. IPF's intrusive symptoms of activity-limiting

\section{KEY MESSAGES}

IPF is an intrusive disease that imposes on patients' lives.

- The lives of informal caregivers of IPF patients are negatively affected in several ways.

Programs for informal caregivers of IPF patients are needed, so they can be the most effective caregiver possible for their patient-loved-ones.

shortness of breath, nagging cough and exhaustion insinuate themselves into patients' lives, leaving them with poor quality of life (QOL) while facing shortened survival. ${ }^{1}$ In contrast to other potentially life-shortening, more gradually progressive conditions (eg, chronic obstructive pulmonary disease, COPD), IPF may develop abruptly and progress rapidly in previously healthy middleaged people-a reality that may impact how patients view living with this disease. Although lung transplantation is an available treatment option for some patients, no therapy has been proved to improve survival in IPF; results from studies have repeatedly shown the median survival from diagnosis to range from 3 to 5 years.

A few studies have been conducted to examine patients' perceptions of being diagnosed with IPF, ${ }^{2-4}$ and in only a handful of studies did investigators focus on how patients live day-to-day with this disease. ${ }^{35}$ IPF causes significant frustrations for patients: as the disease progresses, they become increasingly limited by shortness of breath; supplemental oxygen is ultimately needed by all patients with IPF to combat hypoxaemia; most patients find adapting to the 'sick person' role challenging; and they begin to rely on others to assist with various activities. ${ }^{3}$

As in other chronic, progressive conditions, the effects of IPF extend beyond the patient. The entire household is often adversely affected, particularly those people (spouses, significant others, loved ones) who take on the role of informal caregiver (IC) to the 
patient. Some are unwillingly thrust into this role, while others take it on without hesitation. In either case, these ICs often perceive effects of the disease that patients themselves do not, either because patients have learned to cope by ignoring such effects or because patients have adapted to their more limited role by changing their reference standards and expectations. As witnesses to the ravages of disease progression and patients' declining functional capacity, ICs face many complex challenges. We conducted the current study primarily to learn about the effects of the disease on those closest to patients with IPF. Additionally, given their proximity to patients-a vantage point allowing them to view patients' change over time-ICs' perspectives were expected to allow a fuller understanding of the changing effects of IPF on patients.

\section{METHODS}

We used convenience sampling to recruit ICs from the Interstitial Lung Disease Clinic at National Jewish Health between June 2012 and March 2013. ICs were either contacted via telephone or approached at the time of their loved one's clinic visit. We aimed to include 3-8 ICs/group and conducted focus groups (FGs) at times when all participants could be present. In the patientloved ones, the diagnosis of IPF was made in each case according to the accepted criteria. ${ }^{1}$ We conducted three semistructured FGs of ICs of patients with IPF with two goals in mind: (1) to assess how living with a patient with IPF affects ICs and (2) to gather information from ICs about how they perceive IPF to affect patients. FGs were selected as the appropriate methodology to allow data capture from group discussion and interaction. ${ }^{6}$ FGs were conducted until thematic saturation was achieved. Each FG lasted approximately $1.5 \mathrm{~h}$, was facilitated by a semistructured topic guide designed in part to probe insights generated from the study team's previous work in $\mathrm{IPF}^{3}{ }^{3}$ was conducted in English by a person $(\mathrm{AB})$ trained in qualitative data collection, and was digitally recorded and then transcribed verbatim. As a research coordinator, $\mathrm{AB}$ had no direct or indirect involvement with the care of patient-loved ones.

FG data were analysed in an iterative process involving established qualitative content methods and reflexive team analysis. ${ }^{7-9}$ The qualitative data software program ATLAS.ti V.7.0 (Scientific Software Development, $\mathrm{GmbH}$, Berlin) was used for data management and analysis. Study team members read FG transcripts multiple times to achieve immersion; following team discussion, code categories were developed using an emergent rather than a priori approach, ${ }^{9}$ and one member of the study team (KA) applied the resulting codes to the transcripts. All members of the study team met regularly to check new findings, discuss emergent new codes and themes, and assess the preliminary results of the analysis process. $^{10} 11$

\section{RESULTS}

A total of 14 ICs participated in one of the three FGs $(n=6,5,3)$. The participants' baseline characteristics are presented in table 1. Given that IPF is more common among men than women, the overwhelming majority of ICs were women. Despite using convenience sampling, the patient-loved ones of ICs comprised a group of patients with IPF that spanned the spectrum of disease duration and severity.

\section{Living with a patient who has IPF}

All ICs expressed heartfelt empathy towards their loved ones with IPF ("I just feel so bad for him."). When the

Table 1 Baseline characteristics of informal caregivers to patients with IPF

\begin{tabular}{|c|c|c|c|c|c|c|c|c|}
\hline & \multicolumn{2}{|c|}{$\begin{array}{l}\text { Informal } \\
\text { caregivers }\end{array}$} & \multicolumn{6}{|c|}{ Patients } \\
\hline & Age & $\mathbf{M} / \mathbf{F}$ & Age & M/F & Since Dx & FVC\% & DLCO\% & $\mathrm{O}_{2}$ \\
\hline 1 & 61 & $\mathrm{~F}$ & 70 & $\mathrm{M}$ & 8 years & 47 & 31 & $24 / 7$ \\
\hline 2 & 76 & $\mathrm{~F}$ & 78 & M & 7 years & 52 & 13 & $24 / 7$ \\
\hline 3 & 61 & $\mathrm{~F}$ & 61 & M & 10 months & 70 & 67 & No \\
\hline 4 & 65 & $\mathrm{~F}$ & 66 & M & 1 year & 65 & 37 & $24 / 7$ \\
\hline 5 & 69 & M & 68 & $\mathrm{~F}$ & 6 months & 81 & 51 & No \\
\hline 6 & 69 & $\mathrm{~F}$ & 61 & M & 3 years & 54 & 20 & $24 / 7$ \\
\hline 7 & 69 & $\mathrm{~F}$ & 74 & M & 6 years & 69 & 24 & $24 / 7$ \\
\hline 8 & 58 & $\mathrm{~F}$ & 57 & M & 6 years & 81 & 42 & No \\
\hline 9 & 55 & $\mathrm{~F}$ & 60 & M & 5 years & 53 & 19 & $24 / 7$ \\
\hline 10 & 76 & $\mathrm{~F}$ & 76 & M & 8 years & 48 & 18 & $24 / 7$ \\
\hline 11 & 67 & $\mathrm{~F}$ & 68 & $M$ & 3 years & 99 & 76 & No \\
\hline 12 & 70 & $\mathrm{~F}$ & 78 & M & 3 years & 54 & 16 & $24 / 7$ \\
\hline 13 & 75 & $\mathrm{~F}$ & 77 & M & 3 years & 59 & 33 & $24 / 7$ \\
\hline 14 & 70 & $\mathrm{~F}$ & 73 & $M$ & 5 years & 91 & 21 & $24 / 7$ \\
\hline Mean & $67 \pm 7$ & & $69 \pm 7$ & & $4 \pm 3$ years & $66 \pm 16$ & $33 \pm 19$ & \\
\hline
\end{tabular}


diagnosis of IPF was made, some ICs were "just happy to [finally] have a diagnosis." Some ICs knew just how devastating a diagnosis of IPF can be: while one IC's husband was in recovery after his lung biopsy, she asked the surgeon who knew the diagnosis was almost certainly IPF based on the appearance of the lung, "I just want to know, do we wish it was cancer [something potentially more amenable to therapy than of IPF]?" And although being handed a diagnosis of IPF was 'devastating' to the patient, it was often just as devastating for the ICs. In the words of one, "Once he was diagnosed, I think my whole body just quivered for like two months. It was just like unbelievable." Many ICs used language demonstrative of partnership with their loved one: a "we're-in-this-together attitude" (eg, "We were diagnosed..."; "We hate dragging that oxygen tubing around..."; "We both have a lot of fear..."). Some commented on how, as a pair, they had adapted to allow the patient to participate in accomplishing certain household tasks: "He can't bend over. If he bends over, forget it. So I empty out the bottom of the dishwasher. He empties the top, because he likes to participate."

However, despite this partnership, the 'rollercoaster' of the disease-the good days and troublingly bad days for the patient-was frustrating and, at times, overwhelming for the ICs, leaving them feeling obligated to refocus their lives on their partner. As one said, "Our life revolves around him constantly." Another put it similarly: "That is our life...just what is going on with him." The ICs were forced to 'be flexible' with their social plans, to accept having to cancel last-minute if the patient was not feeling up to going out, to sacrifice some —or, in many cases, much-of their own lives: "What has suffered is my relationships more with my family and my friends, because I'm just busy [being a caregiver to my husband with IPF] all the time." Another noted, "I have to do everything now that he used to do, as well as what I had to do...I don't mind doing it, but it doesn't really give me much time to do anything else." One IC summed it up by noting: "Your life [as the IC] keeps getting smaller, which is really difficult."

Another major contributor to the 'rollercoaster' of IPF was supplemental oxygen $\left(\mathrm{O}_{2}\right)$. In households in which $\mathrm{O}_{2}$ was used by patients with IPF, the impact was profound. One IC said, "It changes your life. I mean 100\%." Another expounded, "[Having to deal with $\left.\mathrm{O}_{2}\right]$ destroys everything, I think, in your normal life that you [once] did." Burdened by the limitations $\mathrm{O}_{2}$ imposed, the ICs were not able to live as carefree as they had prior to dealing with the daily life hassles of having $\mathrm{O}_{2}$ in the household.

The ICs also felt frustrated by their inability to relieve their loved ones' suffering: "There isn't anything you can do. That's the frustrating part for me, when he really starts coughing and you want to do something to help...and there is nothing." The ICs felt completely helpless against IPF's onslaught: "We don't have control [over the disease]...that is one of the most frustrating parts." Besides the frustration and helplessness, the ICs were sad and sorrowful: fighting back tears, one IC said, "I hate like hell to see him like this." Many ICs also experienced intrusive anxiety ("For me it has been a continual state of anxiety [since her husband was diagnosed with IPF]"); worry ("It is a 24 hour a day worry. It just is.") and dread ("What am I going to do with the rest of my life without my husband? It's pretty scary. We've been married for 58 years."). Some even reported complicated feelings about their own relatively good health: as one described, "I almost feel guilty that it is so easy for me to breathe."

Some ICs had not fully adapted to-or were perhaps burned out with - their role as ICs, and their comments suggested resentment. For example, one IC said, "At home he complains a lot...he'll sit down...he says he has to catch up and we'll check the pulse ox [finger pulse oximeter] and it is like...I want to say to him, "It doesn't matter what that pulse ox says." Others put it simply: "I get tired of the coughing" and "It's like living with somebody who has a constant cold [but] the cold never goes away." One IC, clearly aggravated by how much her spouse seemed to always turn the conversation to the status of his IPF, complained that "[He would] talk about it and talk about it and talk about it."

Given this resentment, some expressed a defiant attitude towards the constraints of being an IC. One said, "If I want to be busy doing something, I go ahead and do it...I still worry about him, but I don't show it much." Another stated, "I try to carry on with my life...I'm really active to the point of being selfish...because I'm not going to stay home [all the time]." However, many ICs were more conflicted, explaining how they tried to manage the internal struggle between their perceived duty (and desire) to be supportive of their loved ones with their need to live their own lives: "It's hard to say 'Well, I'm going to go do this'... and know that he would like to go but he really can't." But while ICs recognised that their loved ones had to acknowledge the realities of their illness, they also wanted and needed-and, accordingly, often urged-their loved ones to get on with living, for the ICs' sake and for their own. One IC said, "I have to prod him to get out and do something with friends or to get out of the house." Another added, "I'm always pushing him and I don't know if that is good or bad, but...that's the way it is."

\section{ICs' perceptions of the effects of IPF on patients' lives}

When asked about how IPF has broadly affected their loved ones, the general theme from respondents was complete intrusion. ICs recounted patients' experiences with limited physical activity; bothersome symptoms of shortness of breath, cough and fatigue; altered daily routines; feelings of frustration, anger or fear; and reliance on supplemental $\mathrm{O}_{2}$. In ways insidious and stark, IPF was perceived as thoroughly dominating patients' lives.

ICs described shortness of breath and cough as patients' main symptoms of IPF. These symptoms were 
volunteered immediately in the discussion. The cough was described as dry by most ICs but productive by some ('a ton of mucus') and no more likely to occur at any one time of day than another ("You know, I'm listening to the radio while I'm doing dishes, and I can't hear anything cause he's coughing."). Shortness of breath caused patients to be less physically active than they once were, particularly in outdoor activities such as hiking, riding a bicycle, skiing, running, camping, gardening and even taking walks. On follow-up probing, low stamina or fatigue was also described as present in all patients and very prominent: One IC commented, "He comes home and literally sits in his chair and he naps, and he is tired and he is worn out." Another added that her husband is "totally tired all the time." As the disease progressed, ICs noticed "less and less stamina." One IC noted, "He couldn't do anything [when they moved residences]. He couldn't sit and hand me books to put on the shelf. It just exhausted him too much. Or you know, to hang a rack-put a screw in [the wall]—he just can't do anything like that anymore."

The ICs of patients who were not yet using $\mathrm{O}_{2}$ reported that their loved ones viewed it with trepidation, a looming threat of disease progression and major change. As one IC put it, "He definitely doesn't want to be on oxygen. He really has got a thing about that. I mean...you know...I think that is going to be really a hard stage for us." Another IC said, "We are not dealing with oxygen yet, and I hope we can put that off a long time, but in reality, we know it probably will happen at some point...it is terrifying to me and to him." ICs believed that their loved ones feared the time when $\mathrm{O}_{2}$ would be required because it would be a constant reminder that the patient was losing the battle with IPF. As one IC said, "It's like admitting or, you know, buying into what you really have." Another IC succinctly described how his wife viewed $\mathrm{O}_{2}$ : "It's a failure." Several ICs also reported that patients were apprehensive about using $\mathrm{O}_{2}$ because it would call attention to them in public, allowing others to view them as being ill. The ICs of patients who were using $\mathrm{O}_{2}$ agreed that it was 'enormously limiting' psychologically and physically. One commented, "When my husband went on oxygen, he felt better but he wasn't happy about going on oxygen." Another said, "I think [being prescribed $\mathrm{O}_{2}$ ] is a big step, you know?"

The frustrations of life with IPF often took a significant toll on patients. Many ICs observed that their loved ones had become 'short-tempered,' 'impatient,' 'snappy,' 'cranky' or 'ornery'-even 'selfish.' As one put it, "I definitely see, yeah, a frustration. You know...kind of lashing out sort of thing...just really kind of angry." Another said, "I know my husband, he is just tired of being sick...being sick, and your whole life revolving around it...they just want to be normal." Patients were frustrated and angry, because they were unable to be as active physically as they once were and had to give up activities that they loved. Several ICs shared that they believed their loved ones were scared of the disease progressing and, ultimately, of dying. Indeed, according to their ICs, many patients talked more about their own mortality after their IPF diagnosis, and were increasingly concerned with having their wills and advanced directives in place before it was too late.

While a few ICs described their loved ones as unable to focus on much beyond the status of their disease, many reported that patients seemed to be using denial as a coping mechanism: "I think he is sort of in denial about it. If we don't talk about it, it's not really there." While ICs could tell the disease had progressed by how much more short of breath patients were when doing daily living activities, many reported that these same patients would come home after a clinic visit and say things like, 'Everything is the same. I'm doing great.' About this coping mechanism, one IC speculated, "Maybe they don't want their own family to feel the pain." If true, such efforts were unfortunately fruitless, as ICs remained profoundly affected by the "rollercoaster' of life with IPF.

\section{Conceptual framework for IC's journey through their loved ones' illness}

Figure 1 displays a conceptual framework for understanding the challenges and hurdles faced by ICs of patients with IPF. The 'Potentially beneficial interventions' are based on opinion and experience, not distillations of the data from this study.

\section{DISCUSSION}

We conducted focus groups with ICs of patients with IPF to achieve two goals: (1) to better understand the challenges of being an IC to a patient with IPF and (2) to examine how ICs perceive the impact of IPF on their patient-partners. To our knowledge, this is only the second study to examine the perspectives of ICs of patients with IPF, the only study in which FGs were used and the first using data from US ICs.

The ICs in this study perceived shortness of breath, cough and fatigue/low stamina to be the most troubling of patients' IPF symptoms. These symptoms led to significant limitations in patients' physical activity. In their study, performed in the UK, Bajwah et al ${ }^{12}$ performed in-depth interviews with eight patients and four ICs of advanced patients with IPF as a first step to developing an end-of-life intervention for fibrosing ILD patients and their ICs. All participants identified patients' breathlessness as the 'overwhelming symptom.' Most of their patient-subjects also reported cough as a prominent symptom, and three reported sleep disturbance. Only one of their patient-subjects reported fatigue, whereas the ICs in our study repeatedly mentioned tiredness/ fatigue/low stamina as an intrusive symptom for their partners. Whether there are phenotypic differences between patients with IPF in the UK and the USA, whether there is a difference in the perception of 


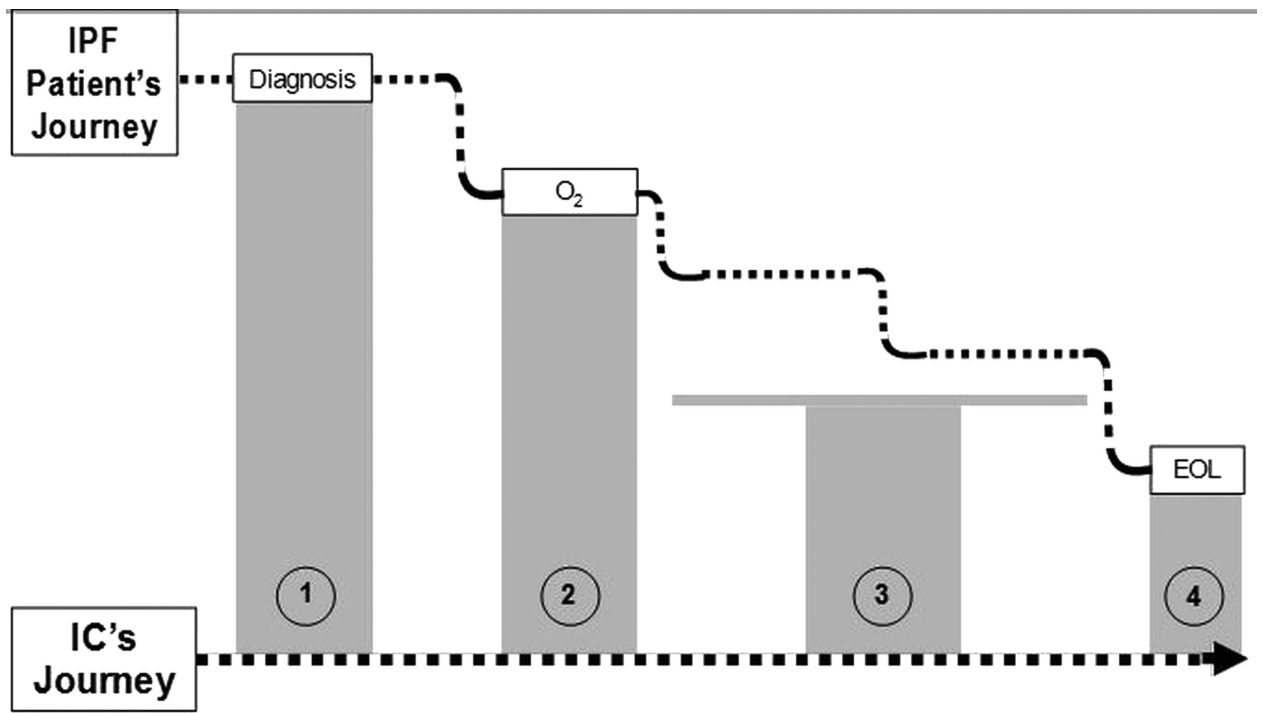

\begin{tabular}{|c|c|c|c|}
\hline \multicolumn{2}{|c|}{ Milestone } & ICs' experiences & Potentially beneficial interventions \\
\hline & Diagnos is & $\begin{array}{l}\text { - Devastation at life-shortening diagnos is } \\
\text { - Fear of unknown } \\
\text { - Wishing the diagnosis were a more treatment } \\
\text { responsive entity than IPF } \\
\text { - Relief that a diagnosis had finally been made } \\
\text { - Commitment to partners hip ('we're in this together") }\end{array}$ & $\begin{array}{l}\text { - Evaluation at center with expertise in IPF } \\
\text { - IPF expert physiciar/practitiones to guide holistic care of } \\
\text { patient, including patient-IC dynamic } \\
\text { - Utilize patient/caregiver resources } \\
\text { - www.PF research.org: www.pulmonaryfibrosis.org } \\
\text { - www.irs pire.com/partners/pulmonary-fibrosis-foundation/ } \\
\text { - www.coalitionfor PF.org } \\
\text { - Maintain s upport network (family, religious, social, spiritual) }\end{array}$ \\
\hline & Life with $\mathrm{O}_{2}$ & $\begin{array}{l}\text { Before } \mathrm{O}_{2} \\
\text { - Trepidation over how life will change } \\
\text { - Hoping } \mathrm{O}_{2} \text { is not needed for a long time } \\
\text { After } \mathrm{O}_{2} \\
\text { - Adapting to impositions of having } \mathrm{O}_{2} \text { in the home } \\
\text { - Maintaining flexibility with social schedule }\end{array}$ & $\begin{array}{l}\text { - To gain perspective on life with supplemental } \mathrm{O}_{2} \\
\text { consider reading the book "Adventures of an Oxyphile }{ }_{2}^{-} \text {by } \\
\text { Thomas L. Petty. MD } \\
\text { - Consider having patient discuss transtracheal oxygen } \\
\text { delivery (TTO) with his/her phys ician and research whether } \\
\text { that would make life with } \mathrm{O}_{2} \text { eas ier }\end{array}$ \\
\hline & $\begin{array}{l}\text { Living with } \\
\text { patient as } \\
\text { dis ease } \\
\text { progresses }\end{array}$ & $\begin{array}{l}\text { - Feeling helpless, can't relieve patient's symptoms } \\
\text { - Living with "oranky" "or nery" "impatient" loved-one } \\
\text { - Learning what to expect as IPF progresses } \\
\text { - Adapting to "new normar" at each s tage of IPF } \\
\text { - Living in an ever-shrinking world } \\
\text { - Trying to find balance between duties as caregiver } \\
\text { and maintaining own identity and independence }\end{array}$ & $\begin{array}{l}\text { - Join online or in-pers on patient/caregiver s upport group } \\
\text {-www.pulmonaryfibros is.org/supportgroups/local } \\
\text { - http://ipftoday.com/support_groups_us_states_international } \\
\text { - Res pite: finding time/activity to promote physical and } \\
\text { emotional well-being of self } \\
\text { - Identify and implement coping/stress management strategies } \\
\text { - Difficult but important discus sions to have: } \\
\text {-resuscitation status of patient } \\
\text {-practical plans for future: affairs (will, insur ance, etc) in order }\end{array}$ \\
\hline & End-of-life & $\begin{array}{l}\text { - Worry and fear about what life will be like without } \\
\text { life partner }\end{array}$ & $\begin{array}{l}\text { - Consider palliative car /hospice involvement } \\
\text { - Continued IPF expert physician/practitioner involvement } \\
\text { - Lean on support network } \\
\text { - Consider formal mentaVbehavior al health therapy }\end{array}$ \\
\hline
\end{tabular}

Figure 1 Conceptual framework for person's journey as IC to IPF patient-loved one. IC, informal caregiver; IPF, idiopathic pulmonary fibrosis; $\mathrm{O}_{2}$, supplemental oxygen.

fatigue by ICs of patients with IPF in the UK versus the USA, or whether differences in study design account for the discrepancy is unclear.

What is clear-and apparent from ICs in both Bajwah et $a l \mathrm{~s}^{12}$ study and ours-is that patients with IPF are frustrated by their inability to escape the weight of their illness, and ICs bear the brunt of that frustration when patients (understandably) 'get nasty,' 'cranky' or 'impatient.' The ICs in our study also saw fear in their loved ones and observed that while this fear manifested for a few as an all-consuming focus on the disease, many patients used denial to cope with this life shortening, unpredictable illness. Both responses caused further distress for ICs.

A central issue in our study, but one that was not reported on in Bajwah and her coinvestigators' manuscript, was $\mathrm{O}_{2}$. The ICs of patients who had not yet been prescribed $\mathrm{O}_{2}$ viewed it forebodingly and, like their patient-partners, as an unwelcome milestone of disease progression and a significant impediment to a carefree lifestyle (for themselves and their partners). The ICs of patients who were using $\mathrm{O}_{2}$ saw their loved ones turn up their $\mathrm{O}_{2}$ flow rate on 'bad' days to try to get relief from increased shortness of breath. Of course, the perceived benefits of $\mathrm{O}_{2}$ are not unique to patients with IPF. In a study conducted by Goldbart $e t a l^{13}$ that focused on perspectives of patients with COPD and their ICs, patients perceived beneficial effects of $\mathrm{O}_{2}$ that included increased physical activity, confidence and independence, and ICs perceived that $\mathrm{O}_{2}$ led to improved QOL in their patient-loved ones. In our study, ICs comments on $\mathrm{O}_{2}$ were predominantly negative: they saw their patient-loved ones tethered to their $\mathrm{O}_{2}$ sources, unable -or more often, unwilling-to stray far from home or for too long a time. Their comments likely stemmed from their perceptions of how $\mathrm{O}_{2}$ imposed adjustments 
to-and limitations on-their own physical and social activities. Supplemental $\mathrm{O}_{2}$ had the effect of shrinking both patients' and ICs' worlds, thus validating the concerns of ICs whose loved ones had not yet been prescribed $\mathrm{O}_{2}$. As Cullen and Stiffler ${ }^{14}$ have described, patients with chronic respiratory conditions must "negotiate lifestyle interference and physical restrictions" caused by $\mathrm{O}_{2}$. In many ways, not only the patient but the entire household must negotiate the interference and restrictions of $\mathrm{O}_{2}$; it became clear in our study that ICs must also 'adapt oxygen to life's circumstances' and figure out how to 'live in a restricted world. ${ }^{14}$

For ICs, there was an emotional cost to living in this restricted world: ours expressed disbelief and devastation at finding out their life partner had an untreatable disease; anger at the overall situation; helplessness because of their inability to relieve their spouses' suffering; fear of the inevitable progression of IPF; and sadness knowing that their partner may live only a few more years (or months). In some cases, the emotional weight on ICs manifested as resentment towards patients.

These findings are not unique to ICs of patients with IPF: Garlo et $a l^{15}$ remind us that people caring for adults with chronic conditions-cancer, heart failure, COPDexperience similar burdens regardless of the patient's illness or disability. How much strain or burden an IC experiences-and the extent to which these negatively impact the physical and emotional well-being of an ICdepends on a number of IC and patient-loved one-related factors, and the complex interplay among them. ${ }^{15}{ }^{16}$ Female ICs appear to experience greater burden than male ICs, even when providing a similar level of care. ${ }^{17} 18$ An IC's or patient's psychological state by and large predicts his own QOL; however, psychological distress in an IC will negatively impact a patient's QOL and vice versa. ${ }^{19}$ And it gets even more complex: when a female IC perceives that she is experiencing vastly more emotional stress over the situation than her male patient-spouse, she may sense emotional abandonment. The same is not true for male ICs. ${ }^{18}$

As we observed in our study, ICs (and other family members) of patients with terminal illnesses make significant life changes and sacrifices to care for their patient-loved ones. ${ }^{20}$ How great those changes and sacrifices need to be, and particularly how well they are accepted and the ease with which they are integrated into an IC's lifestyle, are factors that impact IC strain. Indeed, a growing cache of data suggest that an IC's psychological response to his role as caregiver-rather than the number or difficulty of the tasks they perform to care for their patient-loved one-is a major determinant of IC strain. ${ }^{15}$ Strain creates emotional distress, impairs physical functioning and decreases social contacts among ICs ${ }^{16}$; moreover, IC strain or burden predicts increased distress in patient-loved ones. ${ }^{21}$

ICs are at risk for anxiety and depression; this partly depends on the severity of disease in patient-loved ones, but it also depends on ICs' own physical health states. ${ }^{22}$ ICs with physical ailments-as may occur in the typically older-than-middle-aged group of ICs who care for patients with IPF-are at increased risk for mood disturbance. ${ }^{22}$ Not surprisingly, IC anxiety and depression are linked to ICs' perceptions of strain and burden.

Patient-loved one-factors also affect IC strain or burden. Breathlessness is a particularly distressing symptom for ICs to deal with, ${ }^{23} 24$ and has been linked to impaired QOL among ICs of patients with cancer or COPD. ${ }^{25}$ In agreement with Malik et $a l^{24}$ our data revealed that a patient's struggle to breathe causes in ICs "limitations to shared activities and social life, a loss of companionship, increased feelings of responsibility and helplessness because of their inability to control their loved ones' breathlessness."

This study has limitations. All ICs were partners of patients evaluated at our centre, a quaternary referral centre, and only one was a man; thus, we must consider the possibility that the views of the ICs we enrolled are not fully representative of ICs of patients with IPF in the general population. However, in this largest sample of ICs of patients with IPF ever studied, the external validity of results is supported by the finding that the themes we uncovered overlapped with those from a study published previously. ${ }^{12}$ Importantly, new themes, not reported by other investigators, also emerged from our sample. We did not set out to determine the needs of ICs to develop an intervention for them, per se, although clearly they have needs that are unmet. In our conceptual framework, we describe interventions that may address some of those needs, but this is an area ripe for additional research. In a recently published manuscript, Byrne $e t a l^{26}$ described a protocol for a study aimed at developing a strategy for providing palliative care for patients with IPF and their ICs. The results of that study are eagerly anticipated and will likely prove extremely helpful for ICs of patients with this devastating disease.

In summary, we conducted focus groups with ICs of patients with IPF and learned from them that patients with IPF struggle to find the balance between desperately wanting to live a normal, active life-to maintain their independence-and yielding to a disease that forces them to rely on supplemental oxygen as well as on their ICs' emotional and, often, physical support. Meanwhile, ICs struggle to find balance between providing that support and maintaining their own emotional and physical well-being, freedom and identity. Our suggestions for easing this struggle include establishing IC support groups as a standardised component of care; ensuring that ICs have access to respite so they have time to recharge and maintain their own physical and emotional health; developing an IPF IC-specific educational curriculum that covers topics such as symptoms to expect, how to handle new symptoms/stages of the disease, coping, etc; and encouraging ICs to develop and maintain a support network. We suspect interventions like these would prevent ICs from feeling isolated 
and overwhelmed, while fostering development of a more confident, competent and informed caregiver.

Contributors JJS and $A B$ participated in study conceptualisation. $A B$ participated in data collection. KA, AB and JJS participated in data analysis, manuscript preparation, manuscript editing and approval of the final manuscript.

Funding This study was supported in part by an unrestricted, investigatorinitiated grant from Intermune (JJS is the recipient).

Competing interests JJS is supported in part by a Career Development Award from the NIH (K23 HL092227).

Ethics approval This study was approved by the National Jewish Health Institutional Review Board (Protocol \# HS 2643), and all participants gave signed, informed consent.

Provenance and peer review Not commissioned; externally peer reviewed.

Data sharing statement No additional data are available.

Open Access This is an Open Access article distributed in accordance with the Creative Commons Attribution Non Commercial (CC BY-NC 3.0) license, which permits others to distribute, remix, adapt, build upon this work noncommercially, and license their derivative works on different terms, provided the original work is properly cited and the use is non-commercial. See: http:// creativecommons.org/licenses/by-nc/3.0/

\section{REFERENCES}

1. Raghu G, Collard HR, Egan JJ, et al. An official ATS/ERS/JRS/ ALAT statement: idiopathic pulmonary fibrosis: evidence-based guidelines for diagnosis and management. Am J Respir Crit Care Med 2011:183:788-824.

2. Schoenheit G, Becattelli I, Cohen AH. Living with idiopathic pulmonary fibrosis: an in-depth qualitative survey of European patients. Chron Respir Dis 2011;8:225-31.

3. Swigris JJ, Stewart AL, Gould MK, et al. Patients' perspectives on how idiopathic pulmonary fibrosis affects the quality of their lives. Health Qual Life Outcomes 2005;3:61.

4. Collard HR, Tino G, Noble PW, et al. Patient experiences with pulmonary fibrosis. Respir Med 2007:101:1350-4

5. De Vries J, Seebregts A, Drent M. Assessing health status and quality of life in idiopathic pulmonary fibrosis: which measure should be used? Respir Med 2000;94:273-8.

6. Morgan D. Focus groups. Annu Rev Sociol 1996;22:129-52.

7. Graneheim UH, Lundman B. Qualitative content analysis in nursing research: concepts, procedures and measures to achieve trustworthiness. Nurse Educ Today 2004;24:105-12.

8. Hsieh HF, Shannon SE. Three approaches to qualitative content analysis. Qual Health Res 2005;15:1277-88.
9. Stemler S. An overview of content analysis. Practical Assessment, Research \& Evaluation: PAREonline.net, 2001.

10. Charmaz K. Constructing grounded theory: a practical guide through qualitative analysis. London: Sage, 2006.

11. Teddie C, Tashakkori A. Foundations of mixed methods research: integrating quantitative and qualitative approaches in the social and behavioral sciences. Los Angeles: Sage, 2009.

12. Bajwah S, Higginson IJ, Ross JR, et al. The palliative care needs for fibrotic interstitial lung disease: a qualitative study of patients, informal caregivers and health professionals. Palliat Med 2013;27:869-76.

13. Goldbart J, Yohannes AM, Woolrych R, et al. 'It is not going to change his life but it has picked him up': a qualitative study of perspectives on long term oxygen therapy for people with chronic obstructive pulmonary disease. Health Qual Life Outcomes 2013;11:124

14. Cullen DL, Stiffler D. Long-term oxygen therapy: review from the patients' perspective. Chron Respir Dis 2009;6:141-7.

15. Garlo K, O'Leary JR, Van Ness PH, et al. Burden in caregivers of older adults with advanced illness. J Am Geriatr Soc 2010;58:2315-22.

16. Roth DL, Perkins M, Wadley VG, et al. Family caregiving and emotional strain: associations with quality of life in a large national sample of middle-aged and older adults. Qual Life Res 2009;18:679-88.

17. Miller B, Cafasso L. Gender differences in caregiving: fact or artifact? Gerontologist 1992;32:498-507.

18. Yee JL, Schulz R. Gender differences in psychiatric morbidity among family caregivers: a review and analysis. Gerontologist 2000;40:147-64.

19. Kim Y, Given BA. Quality of life of family caregivers of cancer survivors: across the trajectory of the illness. Cancer 2008;112:2556-68.

20. Emanuel EJ, Fairclough DL, Slutsman J, et al. Understanding economic and other burdens of terminal illness: the experience of patients and their caregivers. Ann Intern Med 2000;132:451-9.

21. Milbury K, Badr H, Fossella F, et al. Longitudinal associations between caregiver burden and patient and spouse distress in couples coping with lung cancer. Support Care Cancer 2013;21:2371-9.

22. Barnes S, Gott M, Payne S, et al. Characteristics and views of family carers of older people with heart failure. Int $J$ Palliat Nurs 2006;12:380-9.

23. Gysels $\mathrm{MH}$, Higginson IJ. Caring for a person in advanced illness and suffering from breathlessness at home: threats and resources. Palliat Support Care 2009;7:153-62.

24. Malik FA, Gysels M, Higginson IJ. Living with breathlessness: a survey of caregivers of breathless patients with lung cancer or heart failure. Palliat Med 2013;27:647-56.

25. Booth S, Silvester S, Todd C. Breathlessness in cancer and chronic obstructive pulmonary disease: using a qualitative approach to describe the experience of patients and carers. Palliat Support Care 2003;1:337-44.

26. Byrne A, Sampson C, Baillie J, et al. A mixed-methods study of the care needs of individuals with idiopathic pulmonary fibrosis and their carers-CaNoPy: a study protocol. BMJ Open 2013;3:e003537. 


\section{Correction}

Belkin A, Albright K, Swigris JJ. A qualitative study of informal caregivers' perspectives on the effects of idiopathic pulmonary fibrosis. BMJ Open Resp Res 2014;1:e000007. doi:10.1136/bmjresp-2013-000007

The heading has changed from 'Pulmonary fibrosis' to 'Interstitial lung disease'.

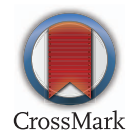

BMJ Open Resp Res 2014;1:e000007corr1. doi:10.1136/bmjresp-2014-000007corr1 